\title{
Pak2 reduction induces a failure of early embryonic development in mice
}

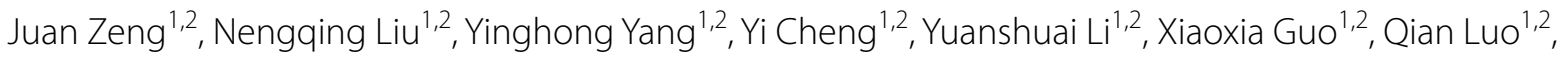 \\ Lifen Zhu ${ }^{1,2}$, Hongmei Guan ${ }^{1,2}$, Bing Song ${ }^{1,2}$ and Xiaofang Sun ${ }^{1,2^{*}}$ (i)
}

\begin{abstract}
Background: The quality of the early embryo is vital to embryonic development and implantation. As a highly conserved serine/threonine kinase, p21-activated kinase 2 (Pak2) participates in diverse biologic processes, especially in cytoskeleton remodeling and cell apoptosis. In mice, Pak2 knock out and endothelial depletion of Pak2 showed embryonic lethality. However, the role of Pak2 in preimplantation embryos remains unelucidated.

Methods: In the present work, Pak2 was reduced using a specific small interfering RNA in early mouse embryos, validating the unique roles of Pak2 in spindle assembly and DNA repair during mice early embryonic development. We also employed immunoblotting, immunostaining, in vitro fertilization (IVF) and image quantification analyses to test the Pak2 knockdown on the embryonic development progression, spindle assembly, chromosome alignment, oxidative stress, DNA lesions and blastocyst cell apoptosis. Areas in chromatin with $\mathrm{\gamma H} 2 \mathrm{AX}$ were detected by immunofluorescence microscopy and serve as a biomarker of DNA damages.

Results: We found that Pak2 knockdown significantly reduced blastocyst formation of early embryos. In addition, Pak2 reduction led to dramatically increased abnormal spindle assembly and chromosomal aberrations in the embryos. We noted the overproduction of reactive oxygen species (ROS) with Pak2 knockdown in embryos. In response to DNA double strand breaks (DSBs), the histone protein $\mathrm{H} 2 \mathrm{AX}$ is specifically phosphorylated at serine 139 to generate $\gamma \mathrm{H} 2 \mathrm{AX}$, which is used to quantitative DSBs. In this research, Pak2 knockdown also resulted in the accumulation of phosphorylated $\mathrm{\gamma H} 2 \mathrm{AX}$, indicative of increased embryonic DNA damage. Commensurate with this, a significantly augmented rate of blastocyst cell apoptosis was detected in Pak2-KD embryos compared to their controls.
\end{abstract}

Conclusions: Collectively, our data suggest that Pak2 may serve as an important regulator of spindle assembly and DNA repair, and thus participate in the development of early mouse embryos.

Keywords: Apoptosis, Embryo, Oxidative stress, Spindle assembly, Pak2

\section{Background}

The early embryonic development of mammals is activated when a mature oocyte $(M I I)$ is fertilized by a mature spermatozoon [1]. After fertilization, the zygote undergoes cleavage divisions from the 2-cell to blastocyst stages, at which point the embryos are implanted into the

\footnotetext{
${ }^{*}$ Correspondence: xiaofangsun@gzhmu.edu.cn

2 Key Laboratory of Reproduction and Genetics of Guangdong Higher Education Institutes, Guangzhou, Guangdong, China

Full list of author information is available at the end of the article
}

mother's uterus on embryonic day 4.5 in mice [2-4]. We now appreciate that embryonic development depends upon precise spatiotemporal regulation of gene expression [5].

Paks (p21-activated kinase) comprise an evolutionarily conserved group of serine/threonine kinases that regulate diverse cellular activities [6]. The mammalian Pak family consists of six members and is divided into two groups: group I is composed of Pak1, Pak2, and Pak3-with Pak1 and Pak3 being tissue-specific and showing the highest levels in brain - whereas Pak2 is ubiquitous [7]; group II

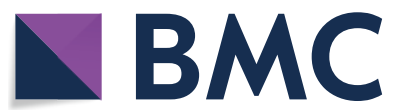

(c) The Author(s) 2021. Open Access This article is licensed under a Creative Commons Attribution 4.0 International License, which permits use, sharing, adaptation, distribution and reproduction in any medium or format, as long as you give appropriate credit to the original author(s) and the source, provide a link to the Creative Commons licence, and indicate if changes were made. The images or other third party material in this article are included in the article's Creative Commons licence, unless indicated otherwise in a credit line to the material. If material is not included in the article's Creative Commons licence and your intended use is not permitted by statutory regulation or exceeds the permitted use, you will need to obtain permission directly from the copyright holder. To view a copy of this licence, visit http://creativecommons.org/licenses/by/4.0/. The Creative Commons Public Domain Dedication waiver (http://creativecommons.org/publicdomain/zero/1.0/) applies to the data made available in this article, unless otherwise stated in a credit line to the data. 
is composed of Pak4, Pak5, and Pak6 [8]. The most fundamental and vital function of Pak2 is to regulate the remodeling of the cytoskeleton [9]. Pak2 can be activated by Cdc42 (GTP) and under various stress conditions, and cleaved caspase 3 also constitutively activates Pak2 during the apoptotic process [10]. Under low-amplitude physiologic forces, Pak2 is protected from proteolysis so as to ensure cellular survival, but under higher-amplitude forces Pak2 is left unprotected and stimulates apoptosis [11]. In addition, Pak2 has been reported to be an important regulator of cellular senescence and organismal aging [12]. Moreover, Pak2 acts as a molecular switch for cytostasis and apoptosis in response to different types and levels of stress, with broad physiologic and pathologic relevance [10]. Pak2 cardiac-deleted mice (Pak2CKO) manifested endoplasmic reticulum stress, cardiac dysfunction, and severe cell death [13]; and Pak2 knockout mice showed embryonic lethality on embryonic day 8.5 (E8.5) due to multiple developmental abnormalities $[7,14,15]$.

Pak2 affects wide range of biological processes and Pak2-null mice are embryonic lethality $[15,16]$. However, the role for Pak2 in early mouse embryonic development remains unclear. In the current study, we explored Pak2 function during the development of early mouse embryos by using a small interfering RNA (siRNA) to silence the Pak2 gene. Our findings indicate that Pak2 is involved in the control of developmental progression and potential of the early embryos of mouse.

\section{Materials and methods \\ Mice}

We used ICR mice, 6-8 weeks of age, in the present study. Experiments were approved by the Third Affiliated Hospital of Guangzhou Medical University Animal Care and Use Committee and conducted in accordance with the guiding principles of the institution.

\section{Antibodies and chemicals}

All the chemicals and reagents were purchased from Sigma unless stated otherwise. Rabbit polyclonal antiPak2 antibody (Cat\#: ab76293) and anti- $\gamma-\mathrm{H} 2 \mathrm{AX}$ (phosphor S139) antibody (Cat\#: ab81299) were obtained from Abcam (Cambridge, MA, USA); mouse monoclonal anti- $\alpha$-tubulin-FITC antibody (Cat\#: F2168) from Sigma (St. Louis, MO, USA); Alexa Fluor 488 goat anti-rabbit IgG $(\mathrm{H}+\mathrm{L})$ (Cat\#: A11008) and CM-H2DCFDA (Cat\#: C6827) from Thermo Fisher Scientific Life Technologies (Massachusetts, MA, USA); an In Situ Cell Death Detection Kit (Cat\#:11684817910) was purchased from Roche (Basel, Switzerland); and HRP-conjugated Affinipure Goat Anti-Rabbit IgG (H+L) (Cat\#:SA00001-2), HRPconjugated Affinipure Goat Anti-Mouse IgG $(\mathrm{H}+\mathrm{L})$
(Cat\#:SA00001-1), and GAPDH Monoclonal Antibody (Cat\#:60004-1g) were purchased from Proteintech (Wuhan, China).

\section{In vitro fertilization and embryo culture}

In vitro fertilization (IVF) was performed according to methods described previously [17]. Adult mice ( $>8$ weeks of age) were used for in vitro fertilization (IVF). Human tubal fluid fertilization medium (HTF; Santa Ana, CA, USA; Cat\#: 90125) containing $1 \%$ bovine serum albumin (BSA; Sigma, St. Louis, MO, USA; Cat\#: A1933-25G) was used as IVF culture medium. Briefly, spermatozoa were collected from the epididymides of adult males and incubated in droplets of IVF culture medium for $1 \mathrm{~h}$ at $37^{\circ} \mathrm{C}$ under 5\% CO2 in humidified air for capacitate. Female mice were injected with $7.5 \mathrm{IU}$ of equine chorionic gonadotropin (eCG; Teikoku Zoki, Tokyo, Japan), and $48 \mathrm{~h}$ later they were injected with $7.5 \mathrm{IU}$ of human chorionic gonadotropin (hCG; Teikoku Zoki, Tokyo, Japan). Thirteen hours after hCG injection, the cumulus-oocyte complexes $(\mathrm{COC})$ were isolated from the oviduct, and capacitated spermatozoa were placed into HTF-droplets containing COCs for co-incubation of at least $5 \mathrm{~h}$. Fertilized zygotes were washed with potassium simplex optimization medium (KSOM; Sigma, St. Louis, USA; Cat\# MR-106-D) and incubated in KSOM medium under paraffin oil. Embryos at $8 \mathrm{~h}, 24 \mathrm{~h}, 48 \mathrm{~h}, 56 \mathrm{~h}, 96 \mathrm{~h}$ after IVF were collected as at pronucleus, 2-cell, 4-cell, 8-cell and blastocysts stage, respectively.

\section{siRNA knockdown}

To explore the functions of Pak2 in early mouse embryos, specific Pak2-siRNA and negative control siRNAs were obtained from Shanghai GenePharma Co, Ltd. The siRNAs were diluted to $1 \mathrm{mM}$ with RNase-free ddH2O and stored in a $-80^{\circ} \mathrm{C}$ refrigerator. When microinjection, the siRNAs were diluted to $20 \mu \mathrm{M}$ and approximately $5-10 \mathrm{pL}$ Pak2-siRNA solution was microinjected into the zygote. Microinjections of small interfering RNAs (siRNA) with a Narishige microinjector were used to knockdown Pak2 in zygotes. The Pak2-siRNA pairs that we used were as follows: forward strand, siRNA\#1, 5'-CCGUGUGCAGAG AGUGUUUTT- 3'; reverse-strand, 5'-AAACACUCU CUGCACACGGTT- $3^{\prime}$; siRNA\#2， 5'-AAUCACAGU UUGAAACCUUTT- $3^{\prime}$; reverse-strand, 5'-AAGGUU UCAAACUGUGAUUGG- $3^{\prime}$ ). A nonspecific siRNA was used as a negative control: forward strand, $5^{\prime}$-UUCUCC GAACGUGUCACGUTT- 3'; reverse-strand, 5'-ACG UGACACGUUCGGAGAATT- $3^{\prime}$ ).

\section{Western immunoblotting analysis}

A total of 70 two-cell embryos were lysed in $12 \mu \mathrm{L}$ of Laemmli sample buffer $(95 \mu \mathrm{L}$ of loading buffer contained 
$5 \mu \mathrm{L}$ of $\beta$-mercaptoethanol) and denatured at $100^{\circ} \mathrm{C}$ for $5 \mathrm{~min}$. Protein samples (70 embryos each sample per lane) were separated on $12 \%$ SDS-PAGE gels and transferred to PVDF membranes, blocked in 5\% skim milk diluted with PBS-Tween $20(0.1 \%$, vol/vol) for $1 \mathrm{~h}$, and then incubated with primary antibody overnight at $4{ }^{\circ} \mathrm{C}$ (Pak2, 1:1000; GAPDH, 1:2000). After at least three washes with PBSTween 20, membranes were incubated with secondary antibody for $1 \mathrm{~h}$ at room temperature. After an additional three washes with PBS-Tween 20, the protein bands were detected with ECL Plus Western Blotting Detection System (GE Healthcare, Piscataway, NJ, USA).

\section{Immunofluorescence}

Early mouse embryos were fixed in $4 \%$ paraformaldehyde (Sigma, St. Louis, USA; Cat\# 158127-100G) for 30 min, permeabilized with $0.1 \%$ Triton X-100 (Sigma, St. Louis, USA; Cat\# T8787-100ML) for $20 \mathrm{~min}$, and then blocked in PBS-BSA (1\%, wt/vol) for $60 \mathrm{~min}$. Embryos were incubated with the primary antibodies anti-Pak2 (1:200) and anti- $\gamma \mathrm{H} 2 \mathrm{AX}$ (1:300), and anti- $\alpha$-tubulin FITC-labeled antibodies $(1: 200)$ overnight at $4{ }^{\circ} \mathrm{C}$. After three washes with PBS-BSA, samples were incubated with secondary antibodies (1:100) for $1 \mathrm{~h}$ at room temperature, and chromosomes were co-stained with propidium iodide (PI; Sigma, St. Louis, USA; Cat\# 81845-25MG) or Hoechst 33342 (Sigma, St. Louis, USA; Cat\# B2261-25MG) for $10 \mathrm{~min}$. Finally, samples were mounted on glass slides with antifade medium (Vectashield, Burlingame, CA; Cat\# H-1000) and then examined via laser-scanning confocal microscopy (LSCM, Leica SP8, Germany).

\section{Measurement of ROS levels}

Changes in intracellular ROS content were determined using CMH2DCFDA (Life Technologies, Invitrogen TM, Carlsbad, CA, USA; Cat\#: C6827). Two-cell embryos were incubated for $20 \mathrm{~min}$ at $37^{\circ} \mathrm{C}$ in $\mathrm{M} 2$ medium (Sigma, St. Louis, USA; Cat\# M7167) containing $5 \mathrm{mM} \mathrm{CMH-}$ 2DCFDA, and after three washes in KSOM medium, embryos were placed on a confocal dish with a microdrop of M2 medium. Images of embryonic fluorescence emission were captured under LSCM and analyzed using ImageJ software.

\section{Statistical analysis}

All experiments were repeated at least three times. Results are presented as means \pm one standard deviation and analyzed by Student's $t$ test. We employed SPSS20.0 for statistical analyses, and $P<0.05$ was considered to be statistically significant.

\section{Results}

\section{Subcellular localization of Pak2 in early embryos}

The subcellular localization of Pak2 in zygotes and pronuclear-, two-cell-, four-cell-, eight-cell-, and blastocyststage embryos was investigated by immunofluorescence staining. Our results revealed that Pak2 signals were distributed throughout the entire embryo, with strong accumulation in the nucleus relative to the cytoplasm (Fig. 1). This particular pattern of Pak2 protein localization implied that it may function in early embryonic development.

\section{Pak2 reduction compromises early developmental potential of embryos}

We next aimed to illustrate the role of Pak2 in early embryonic development of mice. We microinjected specifically designed siRNAs into zygotes to investigate the function of Pak2 during embryonic development, and demonstrated that endogenous Pak2 proteins were reduced by approximately $80 \%$ or $90 \%$ as verified by western blotting analysis (Fig. 2A and B), since the siRNA\#2 knockdown is more efficient, we chose it for subsequent experiments. There were no obvious differences in the morphology of the early mouse embryos between control and Pak2- KD groups (Fig. 2C). However, Pak2-reduction in embryos showed significant developmental delays or cytoplasmic fragmentation (red asterisk) in 4-cell-, 8-cell-, and blastocyst-stage embryos,

Pak2-knockdown also markedly reduced the rate of blastocyst formation (2-cell: $82.3 \pm 1.76 \%, n=118$, control vs. $80.5 \pm 1.82 \%, n=127$, Pak2-KD, $p>0.05$; 4-cell: $71.7 \pm 1.85 \%, n=103$, control vs. $51.8 \pm 1.73 \%, n=82$, Pak2-KD, $p<0.05$; 8-cell: $61.7 \pm 1.93 \%, n=89$, control vs. $21.2 \pm 1.36 \%, n=33$, Pak2-KD, $p<0.05$; blastocyst: $44.3 \pm 1.13 \%, n=63$, control vs. $11.47 \pm 1.62 \%, n=18$, Pak2-KD, $p<0.05$; Fig. $2 \mathrm{C}$ and D). The above observations suggested that the developmental potential of Pak2$\mathrm{KD}$ embryos was impaired during in vitro culture.

\section{Attenuated Pak2 adversely affects spindle assembly and chromosomal congression in mouse embryos}

Since Pak2 has been implicated in regulating cytoskeleton dynamics [18], we herein explored the role of Pak2 in mitosis by treating early embryos with small interfering RNAs, and immunostaining them with an anti- $\alpha$-tubulin antibody to show spindle morphology and counterstaining with PI to observe chromosomes. Most embryos in the control group showed complete bipolar spindles and well-aligned chromosomes (Figure 3Aa). However, the spindles of embryos in the Pak2-KD group revealed multiple defects, such as multipolar (Figure 3Ab, arrows), non-polar spindles (Figure 3Ad, arrows). Moreover, the 


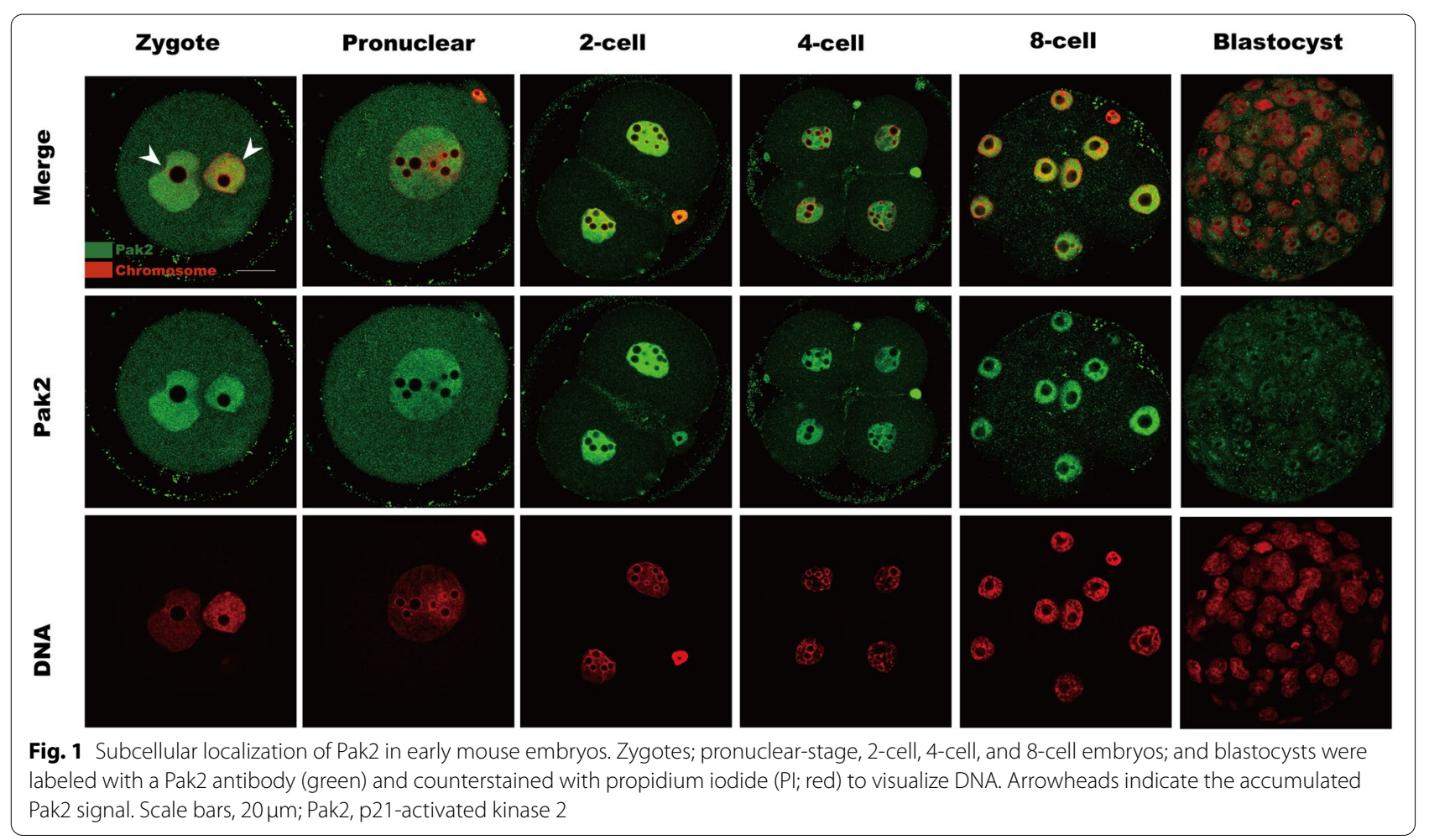

majority of embryos in the Pak2-KD group exhibited severe chromosomal aberrations (Figure 3Abc, arrowheads). The incidence of embryonic spindle defects in the Pak2-KD group was significantly higher than that in the control group $(37.0 \pm 3.89 \%, n=64$, Pak2-KD vs. $17.9 \pm 1.24 \%, n=56$, control, $p<0.05$; Fig. 3B), as was the incidence of chromosomal aberrations (38.8 $\pm 11.77 \%$, $n=67$, Pak2-KD vs. $19.5 \pm 4.62 \%, n=73$, control, $p<0.05$; Fig. 3C).

\section{Reduced Pak2 induces elevated ROS levels in mouse embryos}

It was demonstrated that Pak2 inhibition induced reactive oxygen species overproduction and mitochondrialJNK pathway activation [19]. As production of ROS is a major measure of mitochondrial function [20], we therefore asked whether Pak2 knockdown influences mitochondrial status in the early embryos of mice. To address this question, 2-cell embryos were collected from control and Pak2-KD groups and stained with CMH2DCFDA fluorescent dye for the assessment of ROS generation. Compared with the control group, Pak2-KD treatment significantly increased the levels of ROS in 2-cell embryos (Fig. 4A) as determined by mean fluorescence intensity $(7.9 \pm 1.39, n=24$, control vs. $15.8 \pm 1.41$, $n=28$, Pak2-KD, $p<0.05$; Fig. $4 \mathrm{~B}$ ). These findings imply that Pak2 participates in the regulation of redox homeostasis in mouse preimplantation embryos.

Decreased Pak2 causes the DNA damage in early embryos Histone $\mathrm{H} 2 \mathrm{AX}$ phosphorylation $(\gamma \mathrm{H} 2 \mathrm{AX})$ can be triggered by DNA double-strand breaks (DSBs) [21]. When cellular DSBs occur, H2AX is rapidly phosphorylated in the damaged chromatin, and this activity is localized in nuclear foci [22]. In the present study, $\gamma-\mathrm{H} 2 \mathrm{AX}$ recognizing antibodies were used to quantify DSBs, and we found that $\gamma \mathrm{H} 2 \mathrm{AX}$ foci in Pak-KD embryos (Fig. 5A, arrows) were significantly increased compared to control embryos $(94.3 \pm 2.59, n=32$, control vs. $234.0 \pm 4.31$, $n=37$, Pak2-KD, $p<0.05$; Fig. $5 \mathrm{~A}$ and B). These results imply that Pak2 is essential for genomic integrity of the early embryo.

\section{Pak2 knockdown enhances apoptosis of blastocyst in mouse embryos}

Considering the elevated DNA damage in Pak2-KD embryos, we conducted TUNEL assays to evaluate the apoptotic status in blastocyst-stage embryos. As shown in Fig. 6A, TUNEL-positive nuclei were almost undetectable in control embryos, but we readily observed TUNEL-positive cells in PAK2-KD blastocysts (Fig. 6A, arrows). Quantitative analysis further revealed a significantly increased percentage of Pak2-KD embryos with 

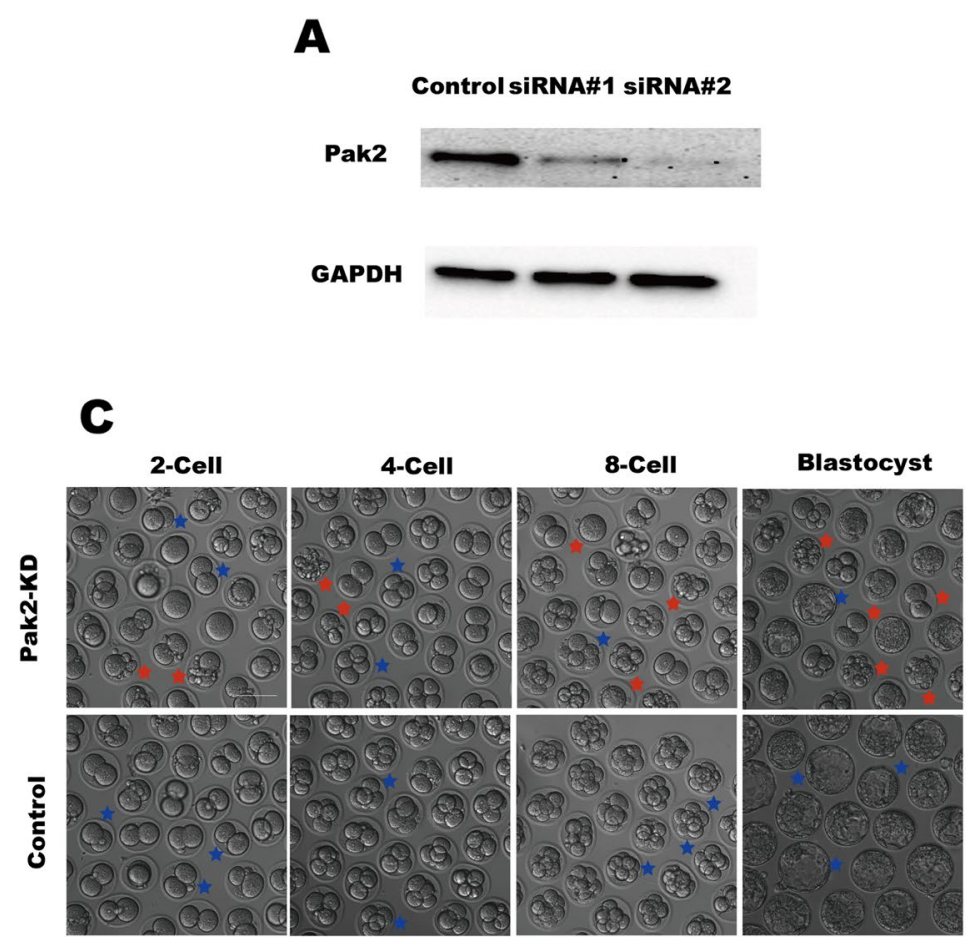

B

$\mathbf{D}$
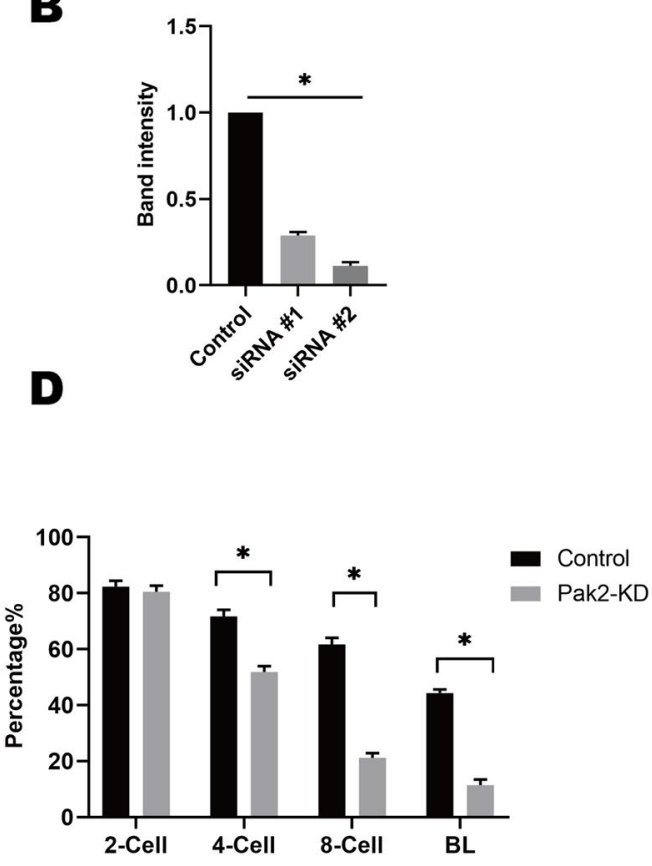

Fig. 2 Pak2 knockdown disrupts the developmental potential of early embryos. In vitro culture of zygotes microinjected with Pak2-siRNA and analysis of developmental progression. A, With GAPDH as a loading control, the efficiency of Pak2 knockdown was confirmed by western blot analysis. B, Band intensity was calculated using ImageJ software (NIH, USA), and the ratio of Pak2/GAPDH expression was normalized and the values are indicated. C, Representative bright-field images of 2-cell embryos, 4-cell embryos, 8-cell embryos, and blastocysts from control and Pak2-KD groups. Bule asterisks indicate examples of normal morphology; red asterisks indicate examples of abnormal morphology (scale bars, $100 \mu \mathrm{m})$. D, Quantification analysis of the rate of 2-cell, 4-cell, 8-cell and blastocyst in control embryos and Pak2-KD embryos. (2-cell: $82.3 \pm 1.76 \%, n=118 \mathrm{vs}$. $80.5 \pm 1.82 \%, n=127$, respectively; 4 -cell: $71.7 \pm 1.85 \%, n=103$ vs. $51.8 \pm 1.73 \%, n=82$, respectively; 8 -cell: $61.7 \pm 1.93 \%, n=89$ vs. $21.2 \pm 1.36 \%$, $n=33$, respectively; blastocyst: $44.3 \pm 1.13 \%, n=63$ vs. $11.47 \pm 1.62 \%, n=18$, respectively). The graph shows the mean perentage $\pm S D$ of the results obtained in three independent experiments. *Significantly different $(p<0.05)$. Pak2, p21-activated kinase 2; SD, standard deviation; Pak2-KD, Pak2 knockdown; BL, blastocyst

TUNEL-positive nuclei relative to controls $(8.9 \pm 0.32$, $n=50$, control vs. $32.8 \pm 1.25, n=37$, Pak2-KD, $p<0.05$; Fig. 6B).

\section{Discussion}

Pak2, as a highly conserved serine/threonine protein kinase, plays a significant role in cell motility, survival, mitosis, and apoptosis [23]. In view of the subcellular localization pattern in early embryos of mice (Fig. 1), we speculated on its involvement in chromatin-related cellular events. To validate our hypothesis, early mouse embryos treated with a Pak2-specific siRNA exhibited a significant increase in abnormal spindle assembly and chromosomal aberrations that contributed to their abnormal early development (Fig. 3). Pak2 has been reported to regulate cytoskeletal dynamics in diverse cell types $[9,18,24,25]$. In a recent study, investigators noted that inactivation of Pak2 caused oxidative stress [26], and that Pak2 was highly activated when mammalian cells were treated with hydrogen peroxide [10]. In glioblastoma A172 cell, Pak2 inhibition induced reactive oxygen species overproduction, mitochondria-JNK pathway activation [19]. In our study, ROS levels were dramatically increased in early embryos when Pak2 activity diminished (Fig. 4), which suggested mitochondrial dysfunction. ROS exert detrimental effects on DNA, RNA, proteins, lipids, and other cellular components - consequently disturbing multiple biologic events that include cellular metabolism, apoptosis, and senescence [27]. Excessive ROS is thus detrimental to normal embryonic development [28].

It was reported that ROS comprised an important factor causing intracellular DNA lesions [29]. $\gamma \mathrm{H} 2 \mathrm{AX}$ has been diffusely serve as a biomarker when detecting DNA damage in preimplantation embryos [30]. $\gamma \mathrm{H} 2 \mathrm{AX}$ accumulation in high-fat diet (HFD) mice zygotes and SETD2-KD mice embryos, the abnormal accumulation of $\gamma \mathrm{H} 2 \mathrm{AX}$ in early embryos contributed to defects in embryonic development, however, a small percentage of embryos still developed to the blastocyst stage [31, 32]. 


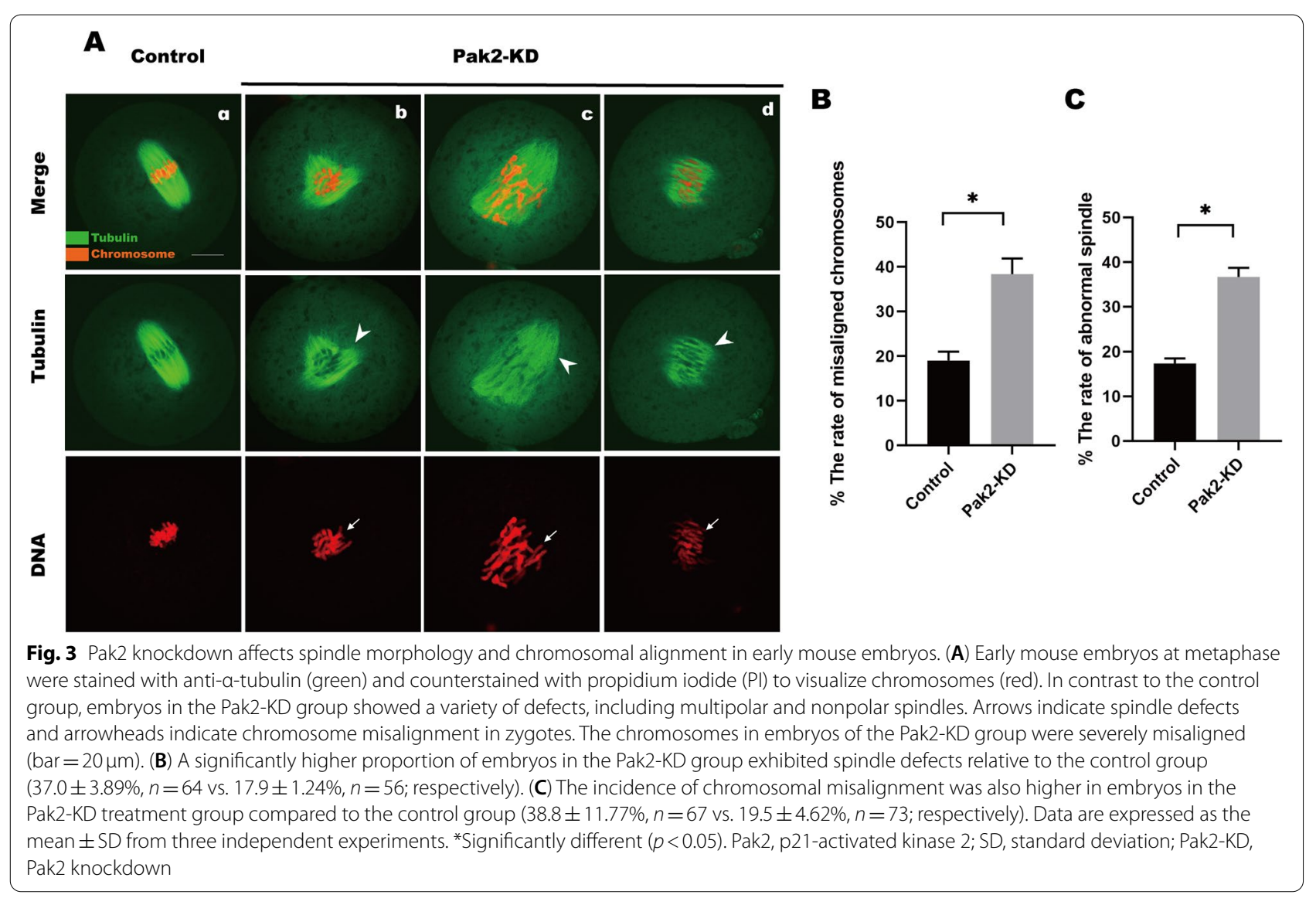

Shortage of conventional G1/S and G2/M checkpoints in the mice zygote mean that embryos carrying extensive DNA lesions can still progress through development, before the establishment of a functional apoptotic pathway in the latter stages of preimplantation embryonic development $[33,34]$. In the present study, the accumulation of phosphorylated $\gamma \mathrm{H} 2 \mathrm{AX}$ was observed in the Pak2-KD embryos (Fig. 5), which indicated increased DNA damage; and continuous DNA lesions compromise the integrity of the genome [35], with genome stability critical for the survival, growth, and normal functioning of organisms [36-38]. ROS induce DNA-base damage, and single- and double-stranded breaks (DSBs) [39]; with DSBs constituting the most dangerous type of DNA lesion in cells [40-43]. To maintain stability, then, the delay or arrest of the cell cycle must occur to allow sufficient time for effective DNA repair [44]. For example, Pak2 dysfunction-induced cell-cycle arrest at the G1 phase caused p27Kip1 accumulation [45]. Our results also revealed that Pak2 reduction resulted in delayed embryonic development and reduced blastocyst-formation rate (Fig. 2).

When the extent of DNA lesions exceed the capacity for recovery, mitosis does not occur and cells undergo apoptosis, senescence, or death [22]. Pak2 is a kinase that can be cleaved by caspase 3 during apoptosis and occupies a dual role in apoptosis: full-length Pak2 then inhibits pro-apoptotic events by phosphorylating Bad28, whereas proteolytic activation of Pak2 p34 leads to apoptosis $[11,45]$. When apoptosis was induced in MCF-7 cells with tumor necrosis factor-a (TNF-a) or Jurkat cells with $\mathrm{C} 2$ ceramide, Pak2 cleavage was also observed [46]. In adult endothelial cells, Pak2 loss leads to severe apoptosis and acute angiogenic defects, and the absence of Pak2 in the endothelium leads to early embryonic lethality due to flawed blood vessel formation [7]. Cytoplasmic fragmentation of early embryos is one of the hallmarks of apoptosis, it was first observed at mice 2-cell embryos $[33,47]$. Our results also showed that the Pak2-KD embryos had a significant cytoplasmic fragmentation (Fig. 2C).

Pak2 plays a vital role in maintenance of endothelial barrier, endothelial cell (EC) migration and angiogenesis $[7,48]$. In mice, homozygous Pak2 KO causes embryonic lethality at E8.5 and endothelial depletion of Pak2 leads to early embryo lethality at E9.5, both embryo death events were associated with angiogenesis defects $[7,15]$. In adult endothelial cells, Pak2 loss leads to severe apoptosis and 

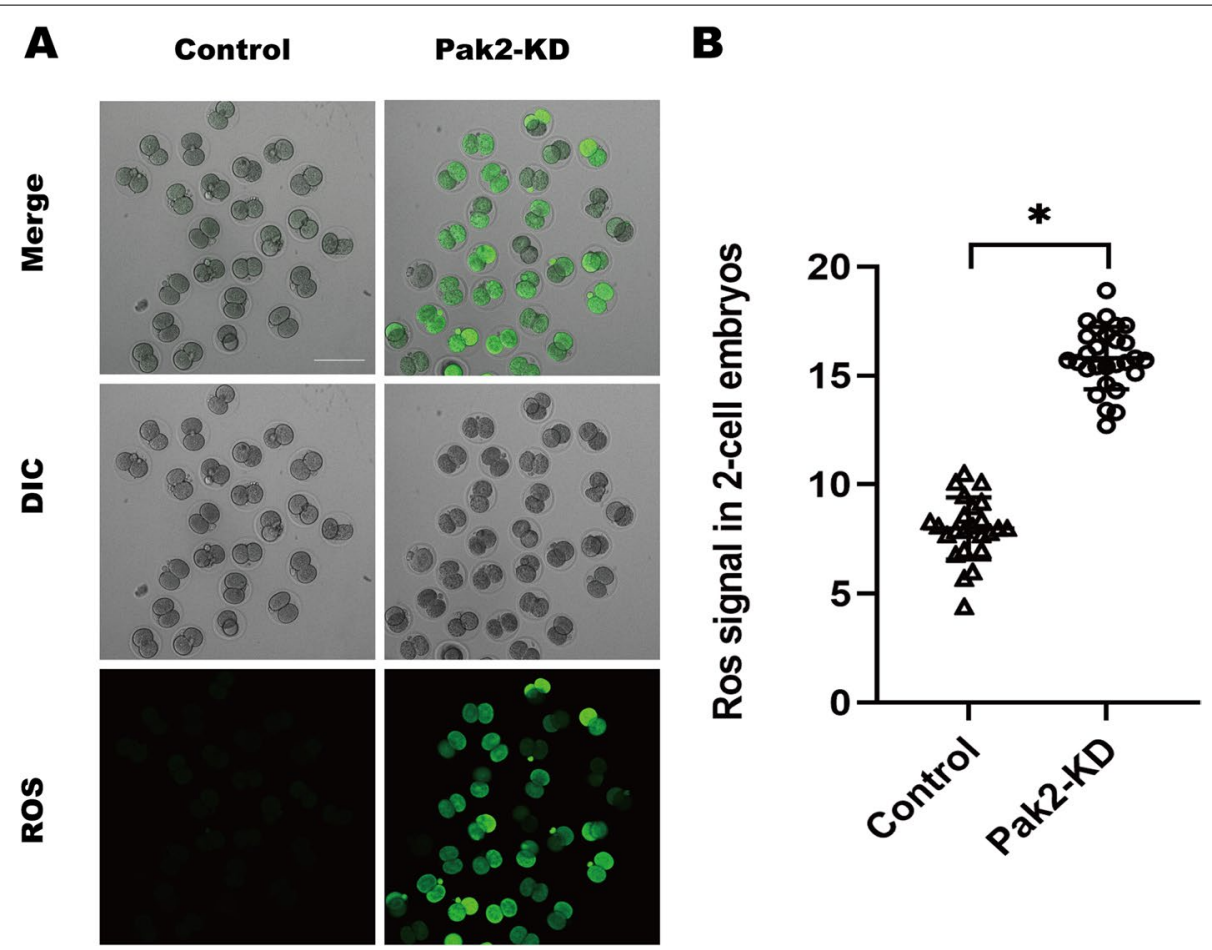

Fig. 4 Pak2 knockdown elevates ROS levels in embryos. (A) Representative images of CM-H2DCFDA fluorescence (green) in 2-cell embryos from control and Pak2-KD groups ( $n=24$ for control group and $n=28$ for Pak2-KD group; scale bars, $120 \mu \mathrm{m}$ ). (B) Quantitative analysis of fluorescence intensity in control and Pak2-KD embryos (7.9 $\pm 1.39, n=24$ vs. $15.8 \pm 1.41, n=28$, respectively). Data are expressed as the mean $\pm S D$ from three independent experiments. *Significantly different $(p<0.05)$. Pak2, p21-activated kinase 2; Pak2-KD, Pak2 knockdown; SD, standard deviation; ROS, reactive oxygen species

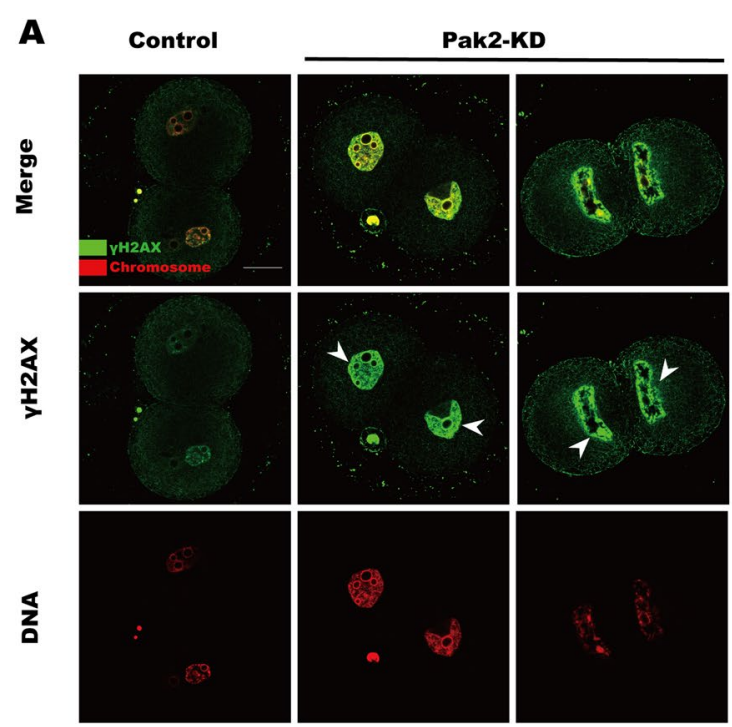

$\mathbf{B}$

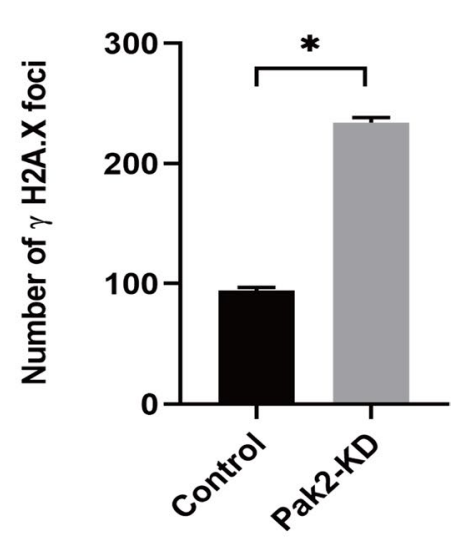

Fig. 5 Pak2 knockdown results in the accumulation of $\mathrm{YH} 2 \mathrm{AX}$ during preimplantation embryonic development. (A) Two-cell embryos were immunostained with an anti- $\gamma \mathrm{H} 2 \mathrm{AX}$ antibody to detect DNA damage (green) and counterstained with PI for DNA (red). Arrows indicate the increased DNA damage in embryos (scale bars, $20 \mu \mathrm{m}$ ). (B) Quantification of the numbers of YH2AX foci in control and Pak2-KD group embryos $\left(94.3 \pm 2.59, n=32\right.$ vs. $234.0 \pm 4.31, n=37$; respectively). Data are expressed as the mean \pm SD from three independent experiments. ${ }^{*}$ Significantly different $(p<0.05)$. Pak2, p21-activated kinase 2; Pak2-KD, Pak2 knockdown; SD, standard deviation; Pl, propidium iodide 

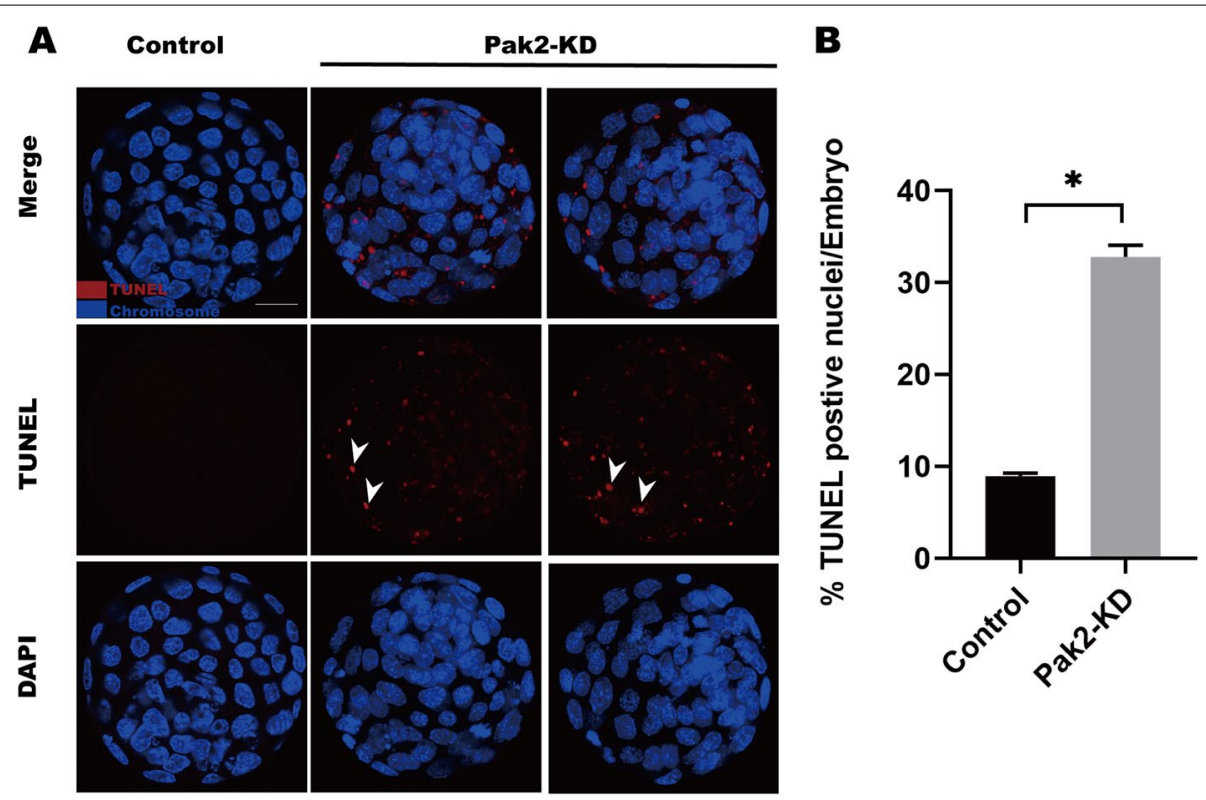

Fig. 6 Pak2-KD induces apoptosis of early mouse embryos. (A) TUNEL analysis of control and Pak2-KD embryos. Embryos were labeled with Hoechst 33342 (blue) for DNA and TUNEL used to assess fragmented DNA (red). Arrows point to apoptotic cells in blastocysts (scale bars, $20 \mu \mathrm{m}$ ). (B) Quantification of control and Pak2-KD group blastocysts with TUNEL- positive nuclei $(8.9 \pm 0.32, n=50$ vs. $32.8 \pm 1.25, n=37$; respectively). Data are expressed as mean percentage \pm SD from three independent experiments. * ${ }^{*}$ ignificantly different $(p<0.05)$. Pak2, p21-activated kinase $2 ;$ SD, standard deviation; Pak2-KD, Pak2 knockdown; TUNEL, terminal deoxynucleotidyl transferase dUTP nick-end labeling

acute angiogenic defects, and the absence of Pak2 in the endothelium leads to early embryonic lethality due to flawed blood vessel formation, angiogenesis defects may be the result of the severe apoptotic events induced by Pak2 deletion [7]. We noted an increased number of apoptotic blastocysts in the Pak2-KD group in the current study (Fig. 6).

Collectively, these data signified that reduction of Pak2 leads to aberrations of embryonic development due to defects in chromosome congression, spindle assembly, increased levels of Reactive Oxygen Species (ROS), DNA lesions and apoptosis.

\section{Conclusions}

In summary, our data indicated that Pak2, as a regulator of spindle assembly, DNA repair and apoptosis, plays a role in the developmental competence of mouse preimplantation embryos.

\footnotetext{
Abbreviations

Pak2: P21-activated kinase 2; Pak2-KD: Pak2 knockdown; ROS: Reactive oxygen species; PI: Propidium iodide; TUNEL: Terminal deoxynucleotidyl transferase dUTP nick-end labeling; BL: Blastocyst.

\section{Acknowledgments}

We thank LetPub (www.letpub.com) for its linguistic assistance during the preparation of this manuscript.
}

\begin{abstract}
Authors' contributions
Juan Zeng and Xiaofang Sun conceived and designed the study. Juan Zeng, Nengqing Liu, Yinghong Yang, Yi Cheng, Yuanshuai Li, Xiaoxia Guo, Qian Luo, Lifen Zhu, Hongmei Guan,and Bing Song collected, arranged, and analyzed the data and wrote the manuscript. All authors read, revised, and finally approved the manuscript.
\end{abstract}

\section{Funding}

This study was supported by the National Natural Science Foundation of China (grant no: 31872800 ) and National Natural Science Foundation of China (grant no: 32070582).

\section{Availability of data and materials}

All data generated or analyzed during this study are available from the corresponding author on reasonable request.

\section{Declarations}

Ethics approval and consent to participate

Experiments were approved by the Third Affiliated Hospital of Guangzhou Medical University Animal Care and Use Committee and conducted in accordance with the guiding principles of the institution.

\section{Consent for publication}

Not applicable.

\section{Competing interests}

The authors declare that they have no conflicts of interest.

\section{Author details}

${ }^{1}$ Department of Obstetrics and Gynecology, Key Laboratory for Major Obstetric Diseases of Guangdong Province, The Third Affiliated Hospital of Guangzhou Medical University, Guangzhou, Guangdong, China. ${ }^{2}$ Key Laboratory of Reproduction and Genetics of Guangdong Higher Education Institutes, Guangzhou, Guangdong, China. 
Received: 27 August 2021 Accepted: 28 November 2021

Published online: 09 December 2021

\section{References}

1. Uzun A, Rodriguez-Osorio N, Kaya A, Wang H, Parrish JJ, Ilyin VA, et al. Functional genomics of HMGN3a and SMARCAL1 in early mammalian embryogenesis. BMC Genomics. 2009;10:183.

2. Grycmacher K, Boruszewska D, Sinderewicz E, Kowalczyk-Zieba I, Staszkiewicz-Chodor J, Woclawek-Potocka I. Prostaglandin F2alpha (PGF2alpha) production possibility and its receptors expression in the early- and latecleaved preimplantation bovine embryos. BMC Vet Res. 2019;15:203.

3. Wennekamp S, Mesecke S, Nedelec F, Hiiragi T. A self-organization framework for symmetry breaking in the mammalian embryo. Nat Rev Mol Cell Biol. 2013;14:452-9.

4. Fujishima A, Takahashi K, Goto M, Hirakawa T, Iwasawa T, Togashi K, et al. Live visualisation of electrolytes during mouse embryonic development using electrolyte indicators. PLoS One. 2021;16:e0246337.

5. Harder MJ, Hix J, Reeves WM, Veeman MT. Ciona brachyury proximal and distal enhancers have different FGF dose-response relationships. PLoS Genet. 2021;17:e1009305.

6. Arias-Romero LE, Chernoff J. A tale of two Paks. Biol Cell. 2008;100:97-108.

7. Radu M, Lyle K, Hoeflich KP, Villamar-Cruz O, Koeppen H, Chernoff J. p21-activated kinase 2 regulates endothelial development and function through the Bmk1/Erk5 pathway. Mol Cell Biol. 2015;35:3990-4005.

8. Kumar R, Sanawar R, Li X, Li F. Structure, biochemistry, and biology of PAK kinases. Gene. 2017:605:20-31.

9. Phee H, Au-Yeung BB, Pryshchep O, O'Hagan KL, Fairbairn SG, Radu M, et al. Pak2 is required for actin cytoskeleton remodeling, TCR signaling, and normal thymocyte development and maturation. Elife. 2014;3:e02270.

10. Huang J, Huang A, Poplawski A, DiPino F Jr, Traugh JA, Ling J. PAK2 activated by $\mathrm{Cdc} 42$ and caspase 3 mediates different cellular responses to oxidative stress-induced apoptosis. Biochim Biophys Acta Mol Cell Res. 2020;1867:118645.

11. Campbell HK, Salvi AM, O'Brien T, Superfine R, DeMali KA. PAK2 links cell survival to mechanotransduction and metabolism. J Cell Biol. 2019:218:1958-71.

12. Lee JS, Mo Y, Gan H, Burgess RJ, Baker DJ, van Deursen JM, et al. Pak2 kinase promotes cellular senescence and organismal aging. Proc Nat Acad Sci U S A. 2019;116:13311-9.

13. Binder P, Wang S, Radu M, Zin M, Collins L, Khan S, et al. Pak2 as a novel therapeutic target for cardioprotective endoplasmic reticulum stress response. Circ Res. 2019;124:696-711.

14. Hofmann C, Shepelev M, Chernoff J. The genetics of Pak. J Cell Sci. 2004;117:4343-54.

15. Kelly ML, Chernoff J. Mouse models of PAK function. Cell Logist. 2012;2:84-8.

16. Jung JH, Traugh JA. Regulation of the interaction of Pak2 with Cdc42 via autophosphorylation of serine 141. J Biol Chem. 2005;280:40025-31.

17. Han L, Wang H, Li L, Li X, Ge J, Reiter RJ, et al. Melatonin protects against maternal obesity-associated oxidative stress and meiotic defects in oocytes via the SIRT3-SOD2-dependent pathway. J Pineal Res. 2017:63:e12431.

18. Reddy PN, Radu M, Xu K, Wood J, Harris CE, Chernoff J, et al. p21-activated kinase 2 regulates HSPC cytoskeleton, migration, and homing via CDC42 activation and interaction with beta-pix. Blood. 2016;127:1967-75.

19. Xing J, Wang Z, Xu H, Liu C, Wei Z, Zhao L, et al. Pak2 inhibition promotes resveratrol-mediated glioblastoma A172 cell apoptosis via modulating the AMPK-YAP signaling pathway. J Cell Physiol. 2020;235:6563-73.

20. Ramalho-Santos J, Varum S, Amaral S, Mota PC, Sousa AP, Amaral A. Mitochondrial functionality in reproduction: from gonads and gametes to embryos and embryonic stem cells. Hum Reprod Update. 2009;15:553-72

21. Bulat T, Keta O, Koricanac L, Zakula J, Petrovic I, Ristic-Fira A, et al. Radiation dose determines the method for quantification of DNA double strand breaks. An Acad Bras Cienc. 2016:88:127-36.
22. Vitale I, Galluzzi L, Castedo M, Kroemer G. Mitotic catastrophe: a mechanism for avoiding genomic instability. Nat Rev Mol Cell Biol. 2011:12:385-92

23. Molli PR, Li DQ, Murray BW, Rayala SK, Kumar R. PAK signaling in oncogenesis. Oncogene. 2009;28:2545-55.

24. Wang Y, Zeng C, Li J, Zhou Z, Ju X, Xia S, et al. PAK2 haploinsufficiency results in synaptic cytoskeleton impairment and autism-related behavior. Cell Rep. 2018;24:2029-41.

25. Kosoff RE, Aslan JE, Kostyak JC, Dulaimi E, Chow HY, Prudnikova TY, et al. Pak2 restrains endomitosis during megakaryopoiesis and alters cytoskeleton organization. Blood. 2015;125:2995-3005.

26. Wang S, Bian W, Zhen J, Zhao L, Chen W. Melatonin-mediated pak2 activation reduces cardiomyocyte death through suppressing hypoxia reoxygenation injury-induced endoplasmic reticulum stress. J Cardiovasc Pharmacol. 2019;74:20-9.

27. Dumollard R, Carroll J, Duchen MR, Campbell K, Swann K. Mitochondrial function and redox state in mammalian embryos. Semin Cell Dev Biol. 2009:20:346-53.

28. Bedaiwy MA, Falcone T, Mohamed MS, Aleem AA, Sharma RK, Worley $S E$, et al. Differential growth of human embryos in vitro: role of reactive oxygen species. Fertil Steril. 2004;82:593-600.

29. Srinivas US, Tan BWQ, Vellayappan BA, Jeyasekharan AD. ROS and the DNA damage response in cancer. Redox Biol. 2019;25:101084.

30. Chang $H$, Chen $H$, Zhang L, Wang $Y$, Xie X, Zhang Y, et al. Effect of oocyte vitrification on DNA damage in metaphase II oocytes and the resulting preimplantation embryos. Mol Reprod Dev. 2019;86:1603-14.

31. Han L, Ren C, Li L, Li X, Ge J, Wang H, et al. Embryonic defects induced by maternal obesity in mice derive from Stella insufficiency in oocytes. Nat Genet. 2018;50:432-42.

32. Li C, Huang Z, Gu L. SETD2 reduction adversely affects the development of mouse early embryos. J Cell Biochem. 2020;121:797-803.

33. Martin JH, Aitken RJ, Bromfield EG, Nixon B. DNA damage and repair in the female germline: contributions to ART. Hum Reprod Update. 2019;25:180-201.

34. Adiga SK, Toyoshima M, Shiraishi K, Shimura T, Takeda J, Taga M, et al. p21 provides stage specific DNA damage control to preimplantation embryos. Oncogene. 2007;26:6141-9.

35. Palou R, Palou G, Quintana DG. A role for the spindle assembly checkpoint in the DNA damage response. Curr Genet. 2017;63:275-80.

36. van Gent DC, Hoeijmakers JH, Kanaar R. Chromosomal stability and the DNA double-stranded break connection. Nat Rev Genet. 2001:2:196-206.

37. Maciejowski J, de Lange T. Telomeres in cancer: tumour suppression and genome instability. Nat Rev Mol Cell Biol. 2017;18:175-86.

38. Niedernhofer LJ, Gurkar AU, Wang Y, Vijg J, Hoeijmakers JHJ, Robbins PD. Nuclear genomic instability and aging. Annu Rev Biochem. 2018;87:295-322

39. Shoji T, Masumoto S, Moriichi N, Ohtake Y, Kanda T. Administration of apple polyphenol supplements for skin conditions in healthy women: a randomized, double-blind, placebo-controlled clinical trial. Nutrients. 2020:12(4):1071.

40. Burma S, Chen BP, Chen DJ. Role of non-homologous end joining (NHEJ) in maintaining genomic integrity. DNA Repair (Amst). 2006;5:1042-8

41. Bhattacharjee S, Nandi S. Choices have consequences: the nexus between DNA repair pathways and genomic instability in cancer. Clin Transl Med. 2016:5:45

42. Sibanda BL, Chirgadze DY, Blundell TL. Crystal structure of DNA-PKCS reveals a large open-ring cradle comprised of HEAT repeats. Nature. 2010;463:118-21.

43. Symington LS, Gautier J. Double-strand break end resection and repair pathway choice. Annu Rev Genet. 2011:45:247-71.

44. Imreh G, Norberg HV, Imreh S, Zhivotovsky B. Chromosomal breaks during mitotic catastrophe trigger gammaH2AX-ATM-p53-mediated apoptosis. J Cell Sci. 1950;2016:129.

45. Koo KH, Kwon H. MicroRNA miR-4779 suppresses tumor growth by inducing apoptosis and cell cycle arrest through direct targeting of PAK2 and CCND3. Cell Death Dis. 2018:9:77

46. Rudel T, Bokoch GM. Membrane and morphological changes in apoptotic cells regulated by caspase-mediated activation of PAK2. Science. 1997:276:1571-4 
47. Byrne AT, Southgate J, Brison DR, Leese HJ. Analysis of apoptosis in the preimplantation bovine embryo using TUNEL. J Reprod Fertil. 1999;117:97-105.

48. Liu J, Fraser SD, Faloon PW, Rollins EL, Vom Berg J, Starovic-Subota O, et al. A betaPix Pak2a signaling pathway regulates cerebral vascular stability in zebrafish. Proc Natl Acad Sci U S A. 2007;104:13990-5.

\section{Publisher's Note}

Springer Nature remains neutral with regard to jurisdictional claims in published maps and institutional affiliations.
Ready to submit your research? Choose BMC and benefit from:

- fast, convenient online submission

- thorough peer review by experienced researchers in your field

- rapid publication on acceptance

- support for research data, including large and complex data types

- gold Open Access which fosters wider collaboration and increased citations

- maximum visibility for your research: over 100M website views per year

At BMC, research is always in progress.

Learn more biomedcentral.com/submissions 